\title{
Gestão de unidades de produção familiar no planalto norte catarinense: percepções sobre o ambiente externo e interno
}

\author{
Luis Augusto Araújo ${ }^{1}$ \\ Alexandre Luís Giehl ${ }^{2}$ \\ Antônio Marcos Feliciano ${ }^{3}$
}

\section{RESUMO}

A gestão é uma prática pela qual os mais de 168 mil estabelecimentos agropecuários familiares catarinenses possam construir seu futuro. O propósito da gestão é a ação e os estabelecimentos terão maior probabilidade de sucesso quanto maior for sua aderência à nova realidade. $\mathrm{O}$ objetivo deste artigo é analisar as percepções de gestores de unidades de produção familiar do Planalto Norte de Santa Catarina, a partir de um conjunto de variáveis do ambiente externo e do ambiente interno que influenciam as estratégias e práticas de gestão. Esse trabalho utiliza a análise SWOT como instrumento metodológico, orientado pelos princípios da pesquisa qualitativa e quantitativa, de cunho exploratório e descritivo. As informações utilizadas nas análises foram obtidas por meio da aplicação de questionário em 20 unidades de produção familiar localizada no município de Canoinhas (SC). Também foram obtidos dados por meio do software de contabilidade eletrônica Contagri. Os resultados apontam que os gestores percebem as variáveis do ambiente externo preponderantemente como oportunidades, percepção que representa 53,3\% do grau de importância total atribuído. O ambiente interno também é percebido essencialmente como fortaleza, percepção que representa $81,5 \%$ das respostas ponderadas. Pensar novas estratégias e produzir inovações são alguns dos desafios da gestão, no sentido de facilitar a reprodução social de unidades de produção familiar para os próximos anos.

Palavras-chave: gestão; agricultura familiar; análise SWOT.

\begin{abstract}
Management is a practice in which more than 168,000 Santa Catarina family agricultural establishments can build their future. The purpose of management is action and establishments are more likely to hit the higher their adherence to the new reality. The aim of this paper is to analyze the perceptions of managers of family production units of the North Plateau of Santa Catarina, from a set of variables of the external environment and internal environment influencing strategies and management practices. This paper uses the SWOT analysis as a methodological tool, guided by the principles of qualitative and quantitative research, exploratory and descriptive nature. The information used in the analysis were obtained by questionnaire 20 family production units located in Canoinhas (SC). They were also obtained data through the electronic accounting Contagri software. The results show that the managers perceive the variables of the external environment mainly as opportunities, perception representing $53.3 \%$ of the total level of importance assigned. The internal environment is also perceived essentially as strength, perception, representing $81.5 \%$ of the weighted answers. Think new strategies and produce innovations are some of the challenges of management in order to facilitate the social reproduction of family production units in the coming years.

Keywords: management; family farming; SWOT analysis

\footnotetext{
${ }^{1}$ Mestre em Economia Aplicada (USP), Analista de Socioeconomia e Desenvolvimento Rural - Centro de Socioeconomia e Planejamento Agrícola da Empresa de Pesquisa Agropecuária e Extensão Rural de Santa Catarina (Epagri/Cepa). Professor da Unisul. E-mail: laraujo@epagri.sc.gov.br

2 Mestre em Agroecossistemas. Analista de Socioeconomia e Desenvolvimento Rural - Centro de Socioeconomia e Planejamento Agrícola da Empresa de Pesquisa Agropecuária e Extensão Rural de Santa Catarina (Epagri/Cepa).

E-mail: alexandregiehl@epagri.sc.gov.br

3 Doutor em Engenharia e Gestão do Conhecimento (PPG-EGC/UFSC). Agente de Pesquisa em Socioeconomia e Desenvolvimento Rural - Centro de Socioeconomia e Planejamento Agrícola da Empresa de Pesquisa Agropecuária e Extensão Rural de Santa Catarina (Epagri/Cepa). Professor do Unifacvest. E-mail: feliciano@epagri.sc.gov.br
} 


\section{INTRODUÇÃO}

Cada vez mais a gestão se constitui em instrumento essencial para garantir o desenvolvimento dos mais diversos setores, inclusive da agricultura e, mais especificamente, no segmento da agricultura familiar. Mais do que isso, a gestão torna-se continuamente um agente de inovação social.

De acordo com Drucker (2012, p. 330), o crescimento exponencial da produção agrícola e da produtividade das terras no mundo foi o evento econômico mais importante no século XX. Este fenômeno foi provocado, principalmente, por uma inovação social ocorrida nos Estados Unidos no início daquele século, que colocou o novo conhecimento ao alcance dos agricultores: o agente rural. Essa inovação social, como aponta o autor, se espalhou pelo mundo, permitindo difundir um crescente conjunto de conhecimentos e informações agrícolas até seus praticantes no campo.

Essa perspectiva apresenta-nos indagações sobre o poder da gestão, como inovação e tecnologia social, no desenvolvimento do rural. A reflexão sobre a importância da gestão pode ser feita sob dois enfoques, que apresentam, entre si, interdependência: como prática à disposição do agricultor e como instrumento de desenvolvimento rural. A preocupação com a gestão no meio rural se justifica pelo fato de qualquer atividade humana exigir eficiência, eficácia e efetividade. Os órgãos de pesquisa e extensão, as cooperativas e demais empresas do agronegócio precisam de informações, conhecimentos e tecnologias adequadas para aconselhar e contribuir com os agricultores na busca da sustentabilidade de suas organizações e na promoção do desenvolvimento rural.

No presente artigo, parte-se da premissa de que é salutar criar conhecimento a partir de uma realidade vivida, para que determinada região consiga ampliar o desenvolvimento de suas unidades de produção agropecuárias. Reforçando tal perspectiva, Secchi (2004, p. 22) afirma que nossas realidades de prática da gestão, condicionadas pelo contexto cultural, político, social e econômico, demandam produção própria de conhecimento ou, pelo menos, uma adequação reflexiva dos conhecimentos concebidos em situações distantes e alheias às que temos.

Os gestores precisam agir e as suas ações terão maior probabilidade de sucesso quanto maior for sua aderência às novas realidades. Diante desse cenário, surgem questionamentos relevantes: em que consiste a gestão de unidades de produção agropecuária familiar? Qual o impacto e a amplitude que as chamadas competências distintivas do agricultor e de sua família e os fatores chave de sucesso assumem na vida organizacional de unidades de 
produção familiar? Não obstante alguns avanços observados em períodos recentes, é possível afirmar que a gestão é uma área de conhecimento emergente. Observa-se uma valorização crescente de tais processos, tidos como essenciais para o adequado desenvolvimento de pessoas, entidades e instituições.

Os processos decisórios na agricultura familiar são complexos e abrangem diversas dimensões, para além do caráter meramente econômico. A tomada de decisão é permeada de questões pragmáticas, pela cultura e pelos valores que o gestor, seja um indivíduo, uma família ou um grupo, carrega consigo. Giehl (2002), ao estudar os processos decisórios que afetam os agricultores assentados, apresenta um conjunto de fatores que têm relevância nesse cenário. $\mathrm{O}$ autor afirma que as decisões do cotidiano de agricultores familiares geralmente têm por base seus projetos de futuro. A interação desses projetos com variáveis relacionadas aos ambientes externo e interno de suas unidades de produção possibilitam a definição de estratégias e tomadas de decisões essenciais para a gestão das mesmas.

Nessa perspectiva, objetivou-se, no presente artigo, analisar as percepções de gestores de unidades de produção familiar, localizadas no Planalto Norte de Santa Catarina, a partir de um conjunto de variáveis de seu ambiente externo e interno, que influenciam na criação de estratégias e nas práticas de gestão. São analisados os resultados parciais de um estudo mais amplo que tem por objetivo avaliar as percepções e a prática da gestão de agricultores familiares dos estados da região Sul do país.

\section{FUNDAMENTAÇÃO TEÓRICA}

A atração exercida pela gestão deve-se muito ao fato de ser uma tarefa multifacetada, além de ser global e atemporal. Crainer (2014) observa que especificar demais o assunto é querer "pregar gelatina na parede". É uma atividade complexa e pessoal que vai além da estratégia, do marketing, de inspirar pessoas, de fazer planejamento e de organizar compromissos e projetos.

Crainer (2014), fazendo referência ao livro Managing de Henry Mintzberg, aponta que gestão é uma prática enraizada no contexto e não uma profissão baseada em pronunciamentos. O contexto é o mais importante para os gestores, apesar da profusão de pronunciamentos e do seu crescimento. Alinhado com a ideia de prática enraizada no contexto e do conceito de estratégia, Mintzberg (2010), afirma que a visão mais influente do processo de formulação de estratégia é representada pela Escola do Design. 
Para Mintzberg, Ahlstrand e Lampel (2010, p. 353), a Escola do Design concebeu a estratégia como tendo quatro elementos que precisam estar equilibrados em um todo coerente. Parafraseando os quatro elementos, ajustados à realidade da presente pesquisa, temos: (1) $\mathrm{O}$ que a unidade de produção agropecuária familiar pode fazer em termos de oportunidades de mercado? (2) O que ela poderia fazer em termos das capacidades atuais? (3) O que os responsáveis pela sua gestão querem fazer? (4) O que ela deve fazer admitindo suas obrigações com a sociedade?

Mendes (2012, p. 33), define estratégia como "a ciência e a arte de desenvolver e utilizar recursos para atingir determinados fins ou resultados desejados". A estratégia acontece em nossa mente, envolvendo a percepção e a intuição, antes de desencadear um processo analítico e sistemático de planejamento.

No contexto da formulação de estratégias, aparece uma questão fundamental: a estratégia a ser implementada por uma unidade de produção agropecuária seria melhor conduzida por um processo de pensamento ou de planejamento estratégico? Até que ponto o planejamento estratégico estraga o pensamento, ao confundir a manipulação de números com a visão real?

Nicolau (2001) destaca que, embora à primeira vista o termo 'estratégia' possa parecer um conceito estabilizado e de sentido consensual, uma análise mais aprofundada permite verificar que a mesma é utilizada num conjunto grande de situações, muitas vezes totalmente distintas entre si. Contudo, a autora também chama a atenção para o fato que fortemente vinculados às definições desse conceito estão os processos que lhe dão origem.

O surgimento e a implementação das estratégias são distintos de uma realidade para outra e resultam de fatores externos e das condições internas de cada organização ou entidade analisada, conclui a autora.

No caso da agricultura familiar, embora adote estratégias diversas no seu cotidiano, tal processo geralmente não é feito de forma sistematizada ou consciente. Batalha, Buainain e Souza Filho (2005) ressaltam que a falta de sensibilização dos agricultores, bem como de grande parte dos técnicos que atuam com os mesmos, reforça a noção de que o bom agricultor é aquele que executa adequadamente as tarefas dentro da propriedade, em especial aquelas diretamente relacionadas à produção agropecuária.

Tal visão reduz a importância da gestão e contribui para a existência de avanços limitados nessa área. 


\section{PROCEDIMENTOS METODOLÓGICOS}

Este artigo tem como referência os princípios da pesquisa qualitativa e quantitativa, a partir de levantamento bibliográfico e aplicação de questionário a agricultores de 20 unidades de produção familiar do município de Canoinhas, Planalto Norte Catarinense, selecionadas intencionalmente.

Participaram desta pesquisa agricultores já anteriormente contemplados no âmbito da parceria $^{4}$ existente entre a Empresa da Pesquisa Agropecuária e Extensão Rural de Santa Catarina (Epagri), a Federação dos Trabalhadores na Agricultura do Estado de Santa Catarina (FETAESC) e a empresa Souza Cruz S.A. Todas as unidades pesquisadas têm em comum a produção do tabaco, com diferentes pesos na composição da renda, conforme apresentado adiante.

O questionário, estruturado com base no método SWOT, contemplou três tópicos principais: (1) caracterização e identificação; (2) variáveis relacionadas ao ambiente externo da unidade; (3) variáveis relacionadas ao ambiente interno. Inicialmente, cada variável foi classificada pelos entrevistados como ameaça ou oportunidade (no caso do ambiente externo) e fortaleza ou fraqueza (ambiente interno).

Depois, solicitou-se a manifestação dos mesmos em relação ao grau de importância da variável, levando em consideração seu impacto nas práticas de gestão na sua unidade: (1) Sem importância; (2) Pouco importante; (3) Importante; (4) Muito importante. Todas as variáveis analisadas neste estudo foram agrupadas em dimensões. No ambiente externo foram utilizadas cinco dimensões: (1) Mudanças na sociedade; (2) Mudanças governamentais; (3) Mudanças econômicas; (4) Mudanças tecnológicas; e (5) Mudanças nos mercados. Quanto ao ambiente interno, utilizou-se seis dimensões: (1) Marketing e comercialização; (2) Gestão da informação; (3) Gestão de pessoas; (4) Finanças e custos; (5) Gestão ambiental; e (6) Gestão da produção.

Para fins de análise, as respostas de cada variável foram ponderadas multiplicando-se as mesmas por valores de 0 a 3, de acordo com o grau de importância: Sem importância (x0); Pouco importante (x1); Importante (x2); Muito importante (x3). Os gráficos apresentados neste artigo indicam o grau de importância total de cada variável e a composição desse grau:

\footnotetext{
${ }^{4}$ A parceria objetiva qualificar os processos de gestão dos agricultores atendidos, principalmente por meio do uso da ferramenta eletrônica de contabilidade denominada Contagri, desenvolvida pela Epagri, e do acompanhamento técnico e gerencial das propriedades.
} 
ameaça e oportunidade ou fraqueza e fortaleza. Considerando-se o total de questionários analisados e a ponderação realizada, o máximo obtido em cada variável são 60 pontos.

É importante ressaltar a multiplicidade de fatores envolvidos no processo de gestão de qualquer empreendimento e, em especial, de propriedades rurais. Porém, neste estudo, optouse por focar a análise nas variáveis relacionadas ao ambiente externo e interno das unidades de produção.

Isso não significa que não se reconheça a importância dos quesitos relacionados diretamente aos gestores, conforme já comentado anteriormente. Também, cabe destacar que as dimensões e variáveis utilizadas neste estudo não se propõem a exaurir as possibilidades existentes.

\section{RESULTADOS E DISCUSSÃO}

A presente seção inicia-se com a caracterização socioeconômica das unidades de produção agropecuária que compõem a amostragem analisada nesta pesquisa. Na sequência, apresentam-se os resultados da pesquisa de campo, relatando-se as percepções dos agricultores sobre variáveis do ambiente externo e interno que afetam a gestão das unidades.

\subsection{Caracterização das unidades de produção agropecuária}

Conforme relatado anteriormente, as unidades de produção agropecuária familiar que compõem a amostragem analisada neste artigo têm em comum principalmente a presença do cultivo de tabaco. Contudo, embora todas sejam unidades de pequeno porte e com perfil familiar, apresentam algumas diferenças relevantes em termos de estrutura, disponibilidade de meios de produção, capital e renda, conforme apresentado nas tabelas 1 e 2 .

A partir dos dados obtidos no Contagri, foram calculados indicadores para a totalidade das unidades analisadas (Média), para o grupo de $20 \%$ de unidades com maior lucro econômico (20\% mais) e $20 \%$ com menor lucro (20\% menos) para o ano agrícola de $2014 / 2015$. 
Tabela 1 - Indicadores de uso dos fatores terra, trabalho e capital das unidades de produção agropecuária, por estrato de participação do lucro.

\begin{tabular}{|c|c|c|c|c|c|c|}
\hline Dimensão & $20 \%$ mais & & Média & \multicolumn{3}{|c|}{$20 \%$ menos } \\
\hline \multicolumn{7}{|l|}{ Tamanho da exploração } \\
\hline Superfície Agrícola Útil - SAU (ha) & 8,50 & & 13,90 & & 19,13 & \\
\hline Área Total (ha) & 14,33 & & 19,33 & & 24,80 & \\
\hline Área Adicional Total (ha) & 0,00 & & 0,25 & & 0,00 & \\
\hline \multicolumn{7}{|l|}{ Unidades animal (efetivo médio/UTH) } \\
\hline UA Total & 0,00 & & 1,70 & & 3,04 & \\
\hline Bovinos & 0,00 & & 1,33 & & 2,80 & \\
\hline Suínos e aves & 0,00 & & 0,19 & & 0,24 & \\
\hline Outros & 0,00 & & 0,18 & & 0,00 & \\
\hline \multicolumn{7}{|c|}{ Trabalho (Unidade de Trabalho Homem - UTH) } \\
\hline UTH Familiar & 1,67 & & 2,75 & & 2,33 & \\
\hline UTH Assalariada & 0,00 & & 0,00 & & 0,00 & \\
\hline UTH Total & 1,67 & & 2,75 & & 2,33 & \\
\hline Capital/UTH & $\mathbf{R} \$$ & $\%$ & $\mathbf{R} \$$ & $\%$ & $\mathbf{R} \$$ & $\%$ \\
\hline Total & $358.742,00$ & $100 \%$ & $235.471,00$ & $100 \%$ & $294.677,00$ & $100 \%$ \\
\hline Terra & $220.000,00$ & $61 \%$ & $140.727,00$ & $60 \%$ & $178.571,00$ & $61 \%$ \\
\hline Construções & $73.427,00$ & $21 \%$ & $39.045,00$ & $17 \%$ & $36.255,00$ & $12 \%$ \\
\hline Giro & $14.962,00$ & $4 \%$ & $10.017,00$ & $4 \%$ & $11.240,00$ & $4 \%$ \\
\hline Máquinas e equipamentos & $50.353,00$ & $14 \%$ & $40.888,00$ & $17 \%$ & $59.714,00$ & $20 \%$ \\
\hline Outros & 0,00 & $0 \%$ & $4.793,00$ & $2 \%$ & $8.896,00$ & $3 \%$ \\
\hline
\end{tabular}

Fonte: Elaboração dos autores com base no Contagri.

Destaca-se, dentre outros, que as unidades com maior desempenho possuem área total $25 \%$ menor que a média e $42 \%$ inferior às unidades de desempenho econômico mais baixo.

No tocante à dimensão trabalho, percebe-se: a menor disponibilidade de força de trabalho familiar nas unidades com melhor desempenho, o que demonstra uma maximização na utilização da mesma; e, em nenhum dos estratos há contratação de trabalhadores assalariados. No que tange ao capital, o grupo denominado " $20 \%$ mais" possui um capital total/UTH 52\% superior à média. A terra constitui o principal elemento na composição do capital total em todos os estratos de unidades, com cerca de $60 \%$.

Em relação à composição da renda bruta total, apresentada na tabela 2, percebe-se que em todos os estratos é predominantemente originária da produção vegetal (92 a 99\%). No grupo das unidades de produção que mais obtiveram lucro, há um maior grau de especialização, o que fica evidente pelo fato de $84 \%$ da renda ser proveniente do tabaco. 
Tabela 2 - Composição da renda bruta total das unidades de produção agropecuárias pesquisadas

\begin{tabular}{|c|c|c|c|c|c|c|}
\hline & \multicolumn{2}{|c|}{$20 \%$ mais } & \multicolumn{2}{|c|}{ Média } & \multicolumn{2}{|c|}{$20 \%$ menos } \\
\hline & $\mathbf{R} \$$ & $\%$ & $\mathbf{R} \$$ & $\%$ & $\mathbf{R} \$$ & $\%$ \\
\hline Renda Bruta Total* & $76.182,00$ & $100 \%$ & $46.255,00$ & $100 \%$ & $39.644,00$ & $100 \%$ \\
\hline Renda bruta total da produção vegetal & $75.182,00$ & $99 \%$ & $42.510,00$ & $92 \%$ & $37.007,00$ & $93 \%$ \\
\hline Tabaco de estufa & $64.122,00$ & $84 \%$ & $32.911,00$ & $71 \%$ & $20.618,00$ & $52 \%$ \\
\hline Soja & 0,00 & $0 \%$ & $5.038,00$ & $11 \%$ & $12.017,00$ & $30 \%$ \\
\hline Espécies florestais (lenha, erva-mate) & $6.100,00$ & $8 \%$ & $2.636,00$ & $6 \%$ & $1.929,00$ & $5 \%$ \\
\hline Plantas para paisagismo & $4.960,00$ & $7 \%$ & 451,00 & $1 \%$ & 0,00 & $0 \%$ \\
\hline Bovinos & 0,00 & $0 \%$ & $2.487,00$ & $5 \%$ & $2.569,00$ & $7 \%$ \\
\hline Outras fontes (animal ou vegetal) & $1.000,00$ & $1 \%$ & $2.731,00$ & $6 \%$ & $2.511,00$ & $6 \%$ \\
\hline
\end{tabular}

*Valor nominal em reais do ano agrícola 2014/15. Fonte: Elaboração dos autores com base no Contagri.

Com base nas informações das tabelas anteriores, podemos destacar alguns pontos: 1) a produção de tabaco de estufa é a atividade mais importante em todos os estratos analisados, sendo responsável por $71 \%$ da renda bruta total, em média; 2) a produção animal é pouco impactante na renda das unidades de produção dessa região; 3) o grupo das unidades $20 \%$ menos" possuem área total superior à média, o que condiz com a importância da produção de grãos, especialmente soja, na composição da sua renda; 4) o estrato com menor disponibilidade de força de trabalho é o " $20 \%$ mais", o que guarda consonância com o fato de ter menor área total e superfície agrícola útil.

\subsection{Percepções sobre o ambiente externo}

O ambiente externo é caracterizado como o conjunto de questões externas à entidade ou organização que está sendo analisada, neste caso, as unidades de produção agropecuária, e que está fora do seu controle. A análise do ambiente externo tem por objetivo identificar as oportunidades e ameaças que se colocam diante das unidades num determinado momento. Como já apontado, no presente estudo as variáveis foram previamente definidas, cabendo aos gestores das unidades avaliá-las como ameaça ou oportunidade e atribuírem-lhe a importância. 
Figura 1 - Grau de importância médio, numa escala ponderada de 0 a 60, das dimensões do ambiente externo.

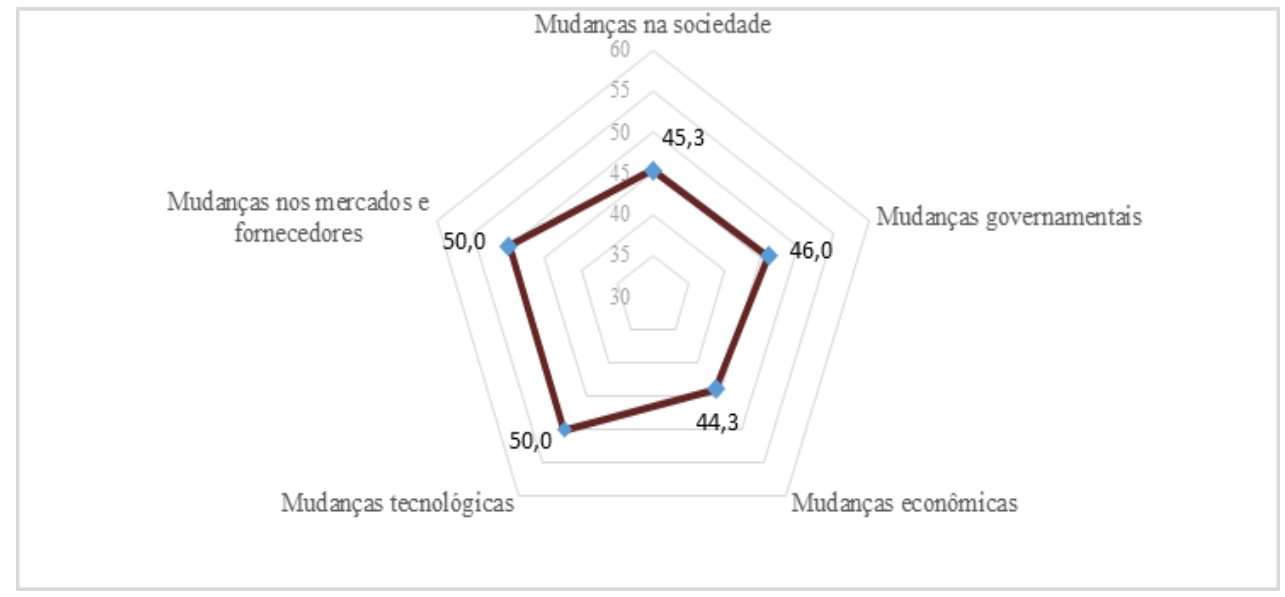

O gráfico acima apresenta o peso atribuído pelos gestores às cinco dimensões que compõem o ambiente externo, independente da classificação como ameaça ou oportunidade. As dimensões que obtiveram a maior pontuação média foram "Mudanças nos mercados e fornecedores" e "Mudanças tecnológicas". Por outro lado, a dimensão "Mudanças econômicas" obteve a menor pontuação. Destaca-se que todas as dimensões obtiveram pontuações médias elevadas, o que denota a importância de todas elas para os gestores, como veremos na sequência. Além disso, os gestores percebem as variáveis do ambiente externo preponderantemente como oportunidades, percepção que representa 53,3\% do grau de importância total atribuído.

\subsubsection{Mudanças na sociedade}

No âmbito da dimensão "Mudanças na sociedade", a variável "Crescimento da urbanização" aparece em primeiro lugar em termos de importância, chamando a atenção o fato de a mesma ser percebida como uma oportunidade para $100 \%$ das respostas ponderadas.

Figura 2 - Percepção e grau de importância das variáveis relacionadas às mudanças na sociedade.

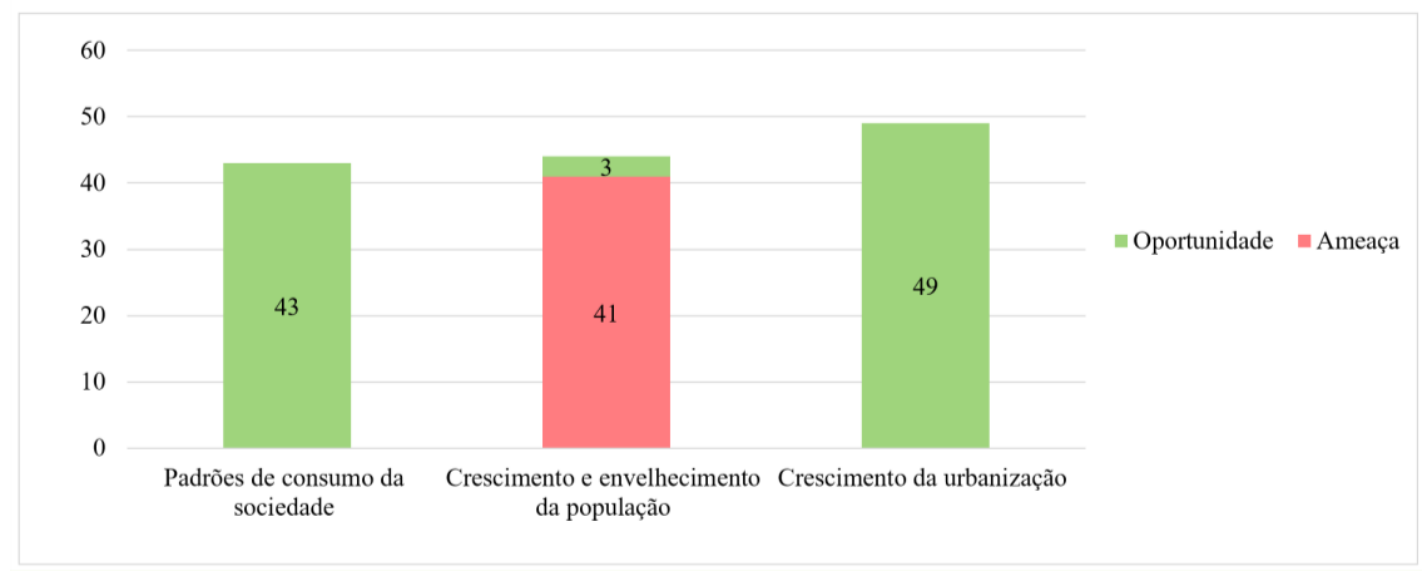


A variável que aborda a influência das mudanças nos padrões de consumo na sociedade sobre a gestão das unidades obteve a menor valorização, sendo, contudo, percebida em $100 \%$ das respostas ponderadas como uma oportunidade.

Em outra direção, a tendência de envelhecimento da população e o aumento populacional em taxas decrescentes foram majoritariamente percebidos como uma ameaça (93,2\% das respostas ponderadas) e, entre as variáveis desta dimensão, apresentou uma valorização intermediária. Apesar de não ser possível afirmar a existência de algum tipo de correlação, pois a pergunta fazia referência ao envelhecimento populacional da sociedade como um todo, é interessante observar que a idade dos proprietários das unidades de produção desta pesquisa varia entre 42 a 65 anos. Embora seja elevado, dados apresentados por Feliciano et al (2015, p.17), demonstram que esse valor está abaixo da faixa etária predominante na população residente no meio rural catarinense, que registra mais de $60 \%$ dos indivíduos acima de 45 anos.

\subsubsection{Mudanças governamentais}

As alterações na legislação previdenciária e ambiental foram as variáveis da dimensão "Mudanças governamentais" mais valorizadas. Foi unânime a percepção que a legislação previdenciária se constitui numa ameaça, enquanto para a legislação ambiental essa percepção vai no sentido contrário, sendo percebida por quase $94 \%$ das respostas ponderadas como uma oportunidade. Esse último resultado causa certa surpresa, tendo em vista ser esperado no meio rural predominar uma percepção negativa em relação à legislação ambiental, em decorrência de restrições de uso e conflitos históricos associados à mesma.

Figura 3 - Percepção e grau de importância das variáveis relacionadas às mudanças no governo.

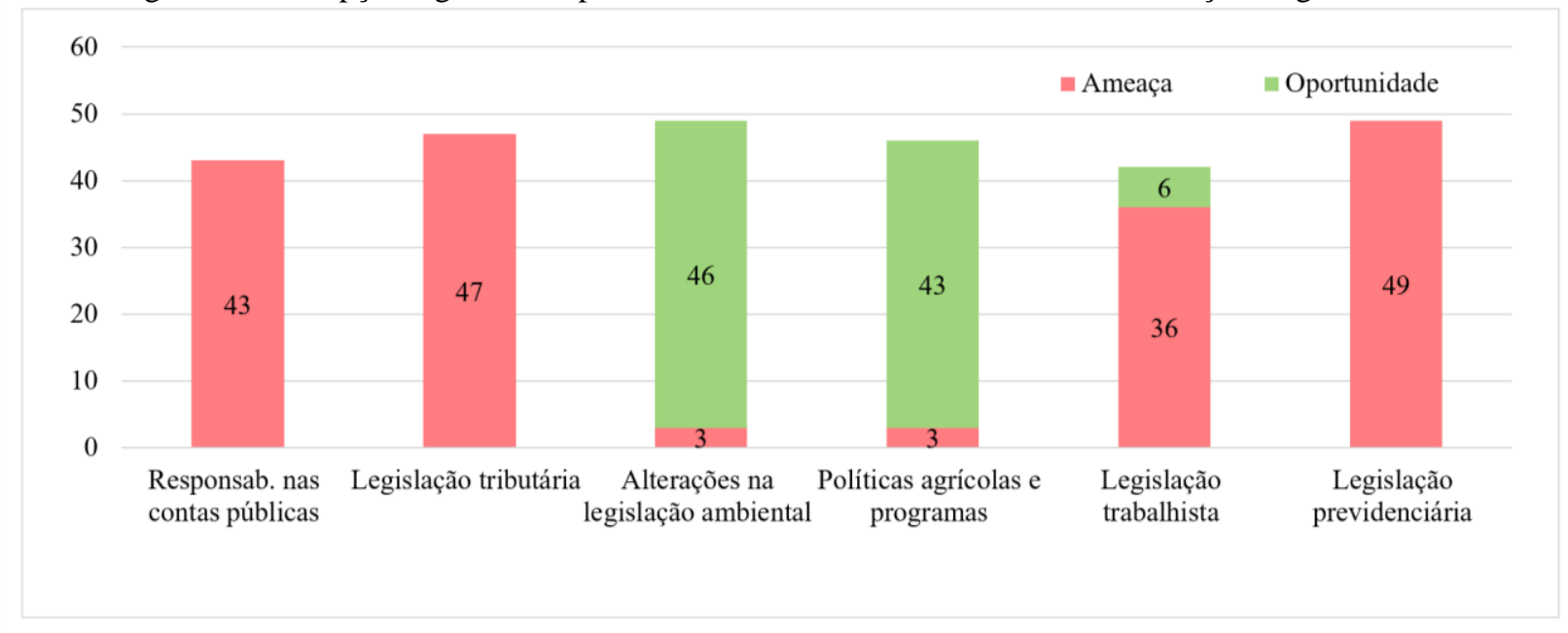


A "Responsabilidade nas contas públicas" e as "Alterações na legislação tributária" são vistas de forma unânime como ameaças, tendo a última variável uma maior valoração pelos respondentes.

Em relação à primeira variável, embora o objetivo inicial fosse avaliar a percepção dos agricultores sobre a responsabilidade nas contas dos governos, é provável que a atual crise econômica e política, muitas vezes associada a um descontrole nos gastos públicos, tenha influenciado nas respostas.

Quanto às alterações nas políticas agrícolas e programas governamentais, os gestores percebem essa variável quase de forma unânime como oportunidade. Ela recebeu uma valoração intermediária entre todas as variáveis que compõe a dimensão mudanças governamentais, com 46 pontos.

Em direção oposta, a legislação trabalhista foi percebida majoritariamente como ameaça. Em relação à última variável, chama-se atenção para o fato de que nenhum dos agricultores entrevistados relata contar com força de trabalho assalariada, conforme demonstrado na Tabela 1. Os receios em relação à legislação trabalhista podem ajudar a explicar essa situação.

De forma geral, essa dimensão teve uma percepção majoritariamente negativa, sendo considerada uma ameaça em mais de 2/3 das respostas ponderadas. Mais uma vez, é bastante provável que o atual momento econômico e político do país tenha influenciado as respostas.

\subsubsection{Mudanças na economia}

O "Crescimento econômico mundial" e o "Crescimento da demanda mundial de alimentos" são percebidos por $100 \%$ dos respondentes como oportunidades, conforme demonstra a Figura 4.

Interessante notar que a primeira recebeu o menor grau de valoração entre as variáveis da dimensão "Mudanças na economia". No caso da demanda de alimentos, destacamos a valorização atribuída a essa variável ( $2^{\mathrm{a}}$ mais pontuada nesta dimensão), uma vez que dentre os agricultores entrevistados predomina o cultivo do tabaco, com ocorrência também de outros cultivos com finalidades não alimentares. 
Figura 4 - Percepção e grau de importância das variáveis relacionadas às mudanças na economia.

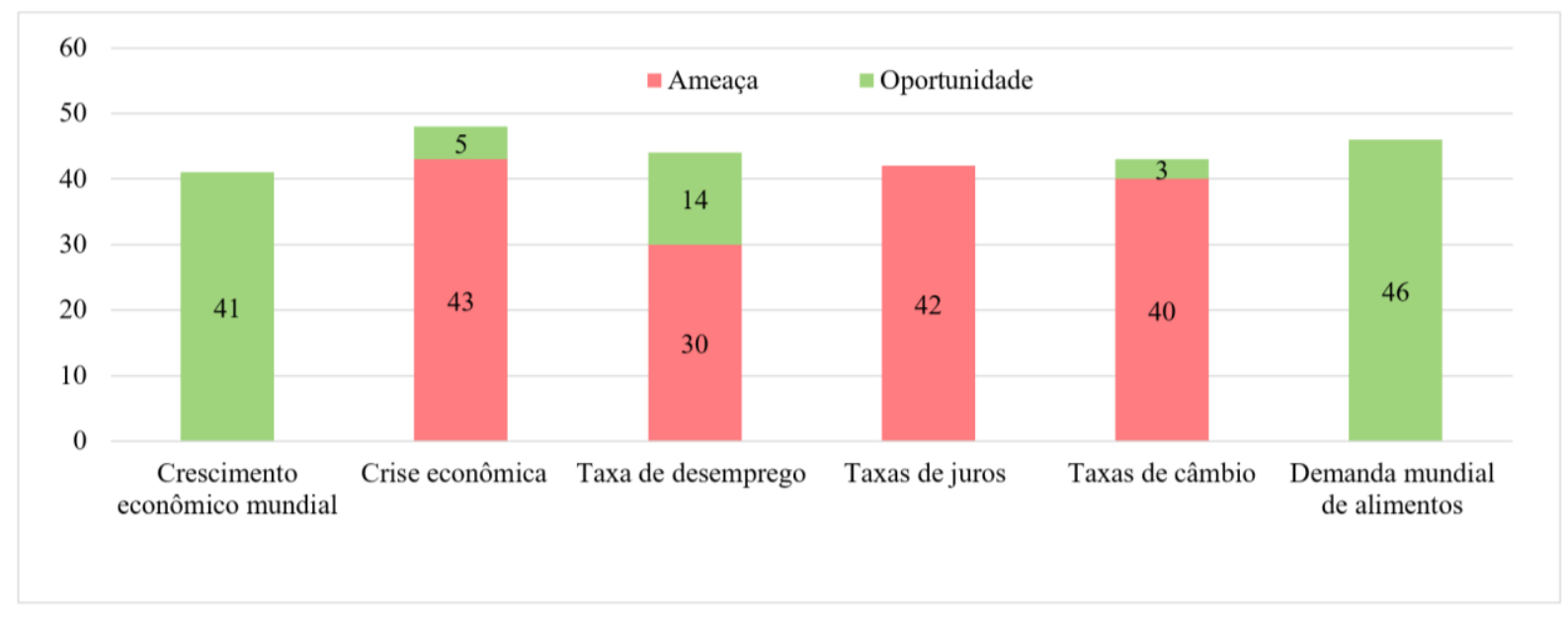

Em sentido contrário, todas as demais variáveis são percebidas majoritariamente como ameaças. Entre elas, a "Crise econômica" e a "Taxa de desemprego", respectivamente, foram as mais valorizadas. Chama a atenção o fato de que a taxa de desemprego foi percebida como oportunidade em $32 \%$ das respostas ponderadas. A explicação para este fato poderia estar relacionada à necessidade de contratação de trabalho temporário que, com o aumento do desemprego, tende a ter seu valor reduzido. Contudo, ressalta-se que nenhum agricultor desta amostra realiza contratação de força de trabalho externa à propriedade, conforme apresentado na tabela 1 .

Por fim, a variável "Taxa de juros" é percebida unanimemente como ameaça e "Taxa de câmbio" atinge 93 \% de avaliação negativa. Deve-se registar ainda que no momento da aplicação do questionário, a taxa Selic era de 14,25\% a.a., uma das mais altas do mundo, o que certamente contribui com tal percepção. Em relação ao câmbio, a importância do tabaco nas propriedades analisadas, produto predominantemente destinado à exportação, possivelmente tem relação com tal percepção.

É importante destacar que, assim como a dimensão anterior, "Mudanças na economia" também foi percebida como ameaça pela maioria das respostas ponderadas $(58,3 \%)$. O atual cenário econômico do país ajuda a explicar tal resultado.

\subsubsection{Mudanças tecnológicas}

Diferente das dimensões anteriormente analisadas, "Mudanças tecnológicas" foi percebida unanimemente como oportunidade. Também foi atribuído a esta dimensão o maior peso dentre todas do ambiente externo. 
O surgimento e difusão de novas tecnologias de produção e de inovações nas tecnologias de informação e de conhecimento são percebidos por $100 \%$ dos respondentes como sendo oportunidades. Ressalta-se que às inovações nas tecnologias de informação e de conhecimento foi atribuído uma valoração um pouco superior àquela destinada às novas tecnologias de produção.

Figura 5 - Percepção e grau de importância das variáveis relacionadas às mudanças tecnológicas.

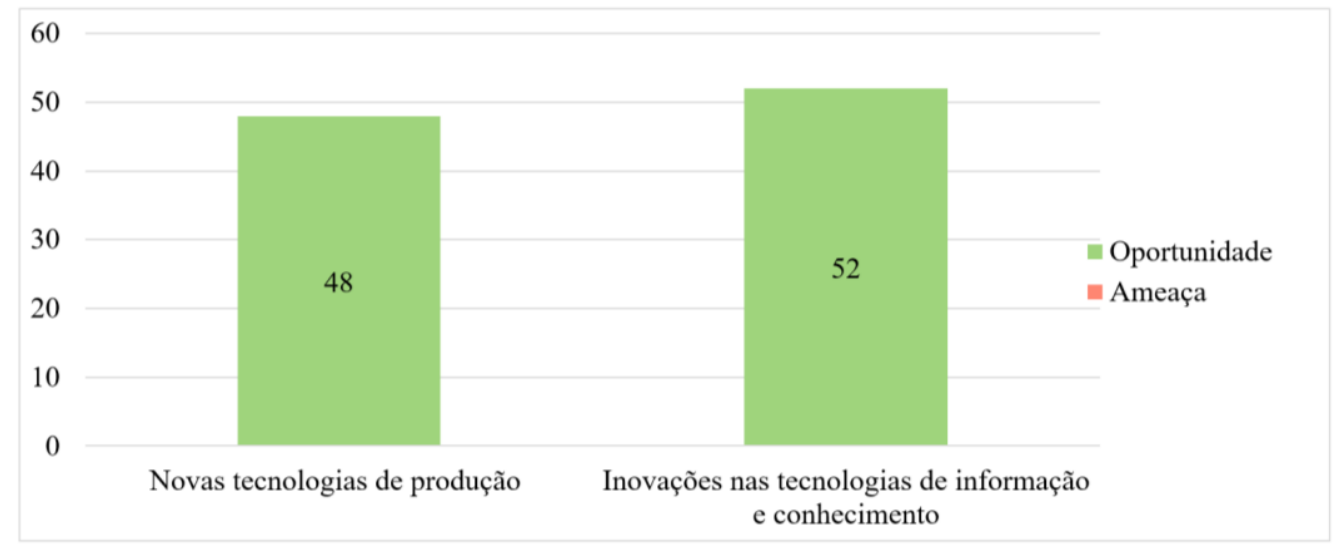

Convém confrontar a percepção positiva das mudanças tecnológicas do ambiente externo com algumas variáveis do ambiente interno. Como veremos em seguida, os respondentes percebem a variável "Informações e conhecimentos por meio de técnicos" (que poderia ser traduzida por acesso aos serviços de assistência técnica e extensão rural) como muito importantes na gestão dos negócios das unidades de produção.

No contexto da percepção positiva relacionada às mudanças tecnológicas, as questões que se colocam são: como desenvolver pesquisas e sistemas de inovação que garantam às unidades de produção agropecuária um fluxo contínuo de inovações para o mercado? Que estratégias de extensão rural e de assistência técnica deveriam ser implementadas para favorecer a prosperidade dessas unidades de produção agropecuárias?

\subsubsection{Mudanças no mercado}

O surgimento de "Novas possibilidades de comercialização" é percebido por $100 \%$ dos respondentes como sendo uma oportunidade, além de ter sido a variável mais valorizada desta dimensão, juntamente com "Preço dos insumos agrícolas". 


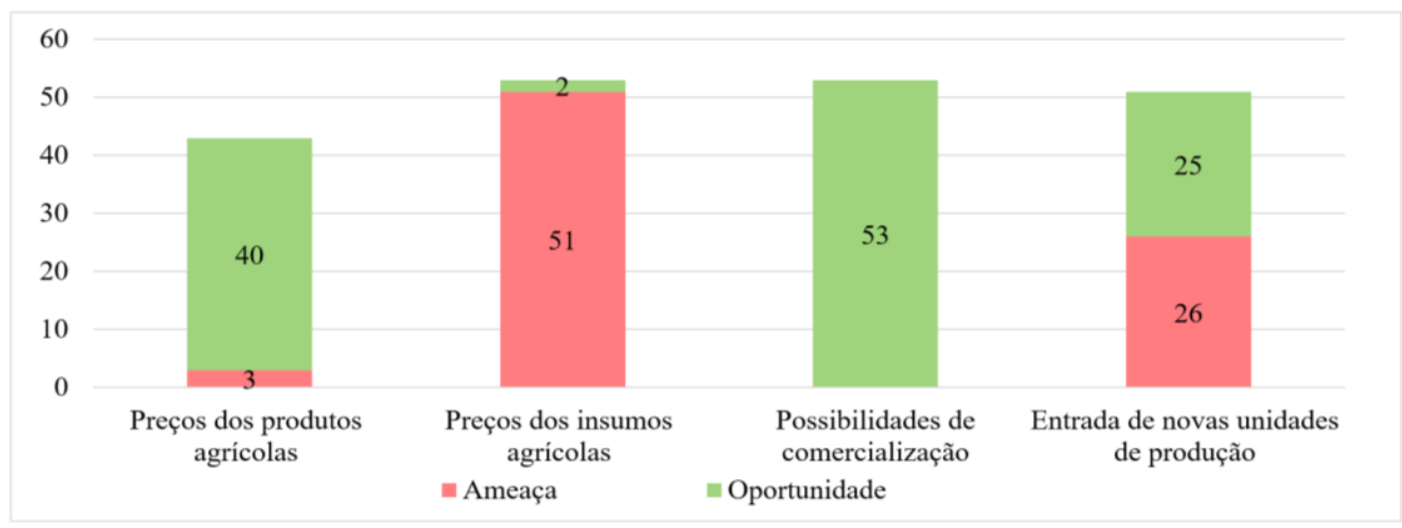

Figura 6 - Percepção e grau de importância das variáveis relacionadas às mudanças no mercado.

Para Wilkinson (2014, p. 10), as oportunidades de inserção econômica se multiplicam por conta da demanda para produtos diferenciados, a exemplo dos orgânicos e dos produtos certificados, enquanto que para outros, as cadeias tradicionais mantêm-se como a melhor opção. Ressalta-se que no caso dos agricultores aqui analisados, como já detalhado anteriormente, em termos de contribuição na renda bruta predomina o tabaco, seguido da soja.

É importante destacar que, numa economia de mercado, o principal sinalizador para a tomada de decisões é o seu sistema de preços. No caso desta pesquisa, de forma quase unânime os respondentes julgam as variações de "Preços dos insumos agrícolas" como uma ameaça muito importante. Por outro lado, os "Preços dos produtos agrícolas" são apontados como uma oportunidade de grande significância. Levando-se em consideração o fato dos agricultores serem tomadores de preço de ambos os lados, insumos e produtos agrícolas, chama a atenção a percepção positiva que os mesmos têm com relação aos preços dos produtos agrícolas. Isso pode estar associado à predominância do tabaco nas unidades, uma vez que essa cultura é comumente tida como de alta rentabilidade, não obstante outras características que possam ser associadas à mesma.

Diferentemente das variáveis anteriores, a "Entrada de novas unidades de produção" apresenta clara indefinição, dado que $51 \%$ do grau de importância atribuído relaciona-se à percepção de ameaça e $49 \%$ de oportunidade. Esse resultado não causa surpresa, considerando o fato dos agricultores estarem operando num mercado bastante competitivo para a principal atividade de seu sistema de produção. Essa percepção também demonstra que, embora a margem seja pequena, há uma predominância do senso de competição em relação ao de cooperação. Contudo, ao analisarmos a baixa participação desses agricultores em entidades associativas, como veremos adiante, era de se esperar inclusive uma maior identificação desta variável como ameaça. 


\subsection{Percepções sobre o ambiente interno}

No método SWOT, a análise do ambiente interno tem por perspectiva a identificação de pontos fortes e fracos das unidades estudadas, bem como o dimensionamento da importância dos mesmos. A partir disso, é possível ao gestor construir estratégias que mantenham ou potencializem as fortalezas e minimizem ou anulem as fraquezas.

A Figura 7 apresenta a pontuação média atribuída a cada uma das seis dimensões que compõem o ambiente interno analisado nesta pesquisa.

Figura 7 - Grau de importância médio, numa escala ponderada de 0 a 60, para cada uma das dimensões do ambiente interno.

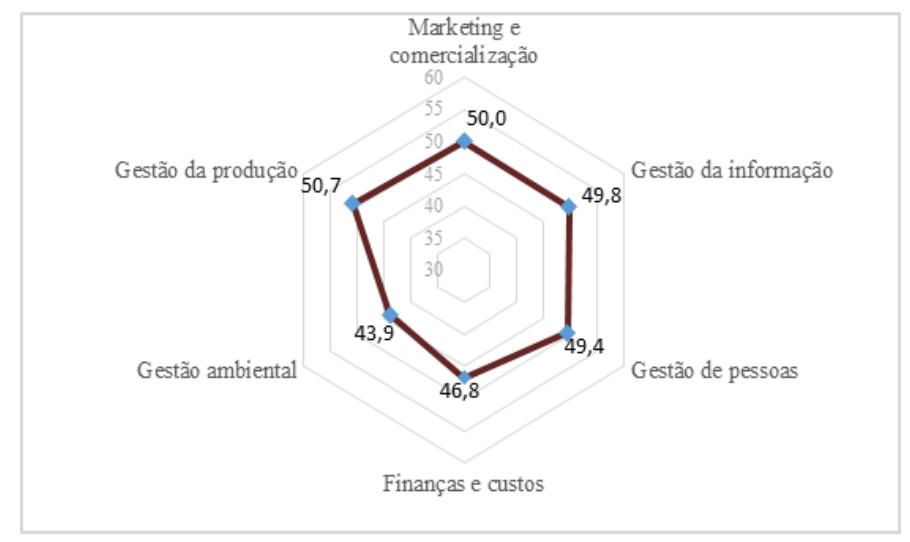

De forma mais significativa que o ambiente externo, o ambiente interno é percebido essencialmente como fortaleza, percepção que representa $81,5 \%$ das respostas ponderadas. A dimensão que recebeu a maior pontuação média, a partir das respostas ponderadas, foi "Gestão da produção". Já a dimensão "Gestão ambiental” recebeu a menor pontuação. Não obstante tais variações, todas as dimensões receberam pontuações consideradas elevadas, o que indica que as mesmas são importantes nos processos decisórios dos gestores. $\mathrm{Na}$ sequência cada dimensão será discutida de forma mais detalhada.

\subsubsection{Marketing e comercialização}

A partir de uma visão geral sobre os resultados das variáveis, todas foram consideradas muito importantes no âmbito da gestão das unidades de produção, com maior destaque para "Qualidade do (s) produto (s)", "Diversidade de produtos" e "Forma (s) de venda do (s) produto (s)" (direta ao consumidor, entrega para intermediários, feiras, estabelecimento comerciais, Programa de Aquisição de Alimentos - PAA, integração, entre 
outras). Essa última variável foi considerada unanimemente como uma fortaleza pelos participantes da pesquisa, conforme apresentado na Figura 8.

Figura 8 - Percepção e grau de importância das variáveis relacionadas ao marketing e comercialização.

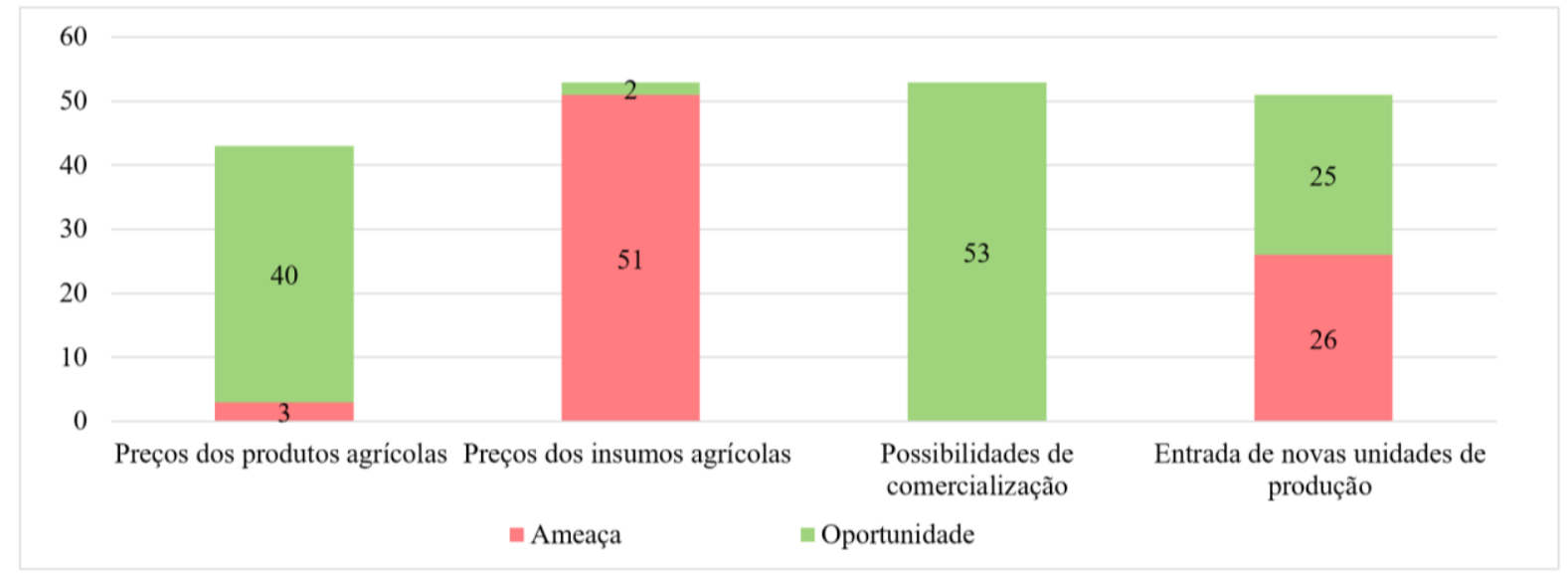

É possível destacar também como variáveis importantes os "Preços do (s) produto (s) " e o "Volume de produção". Embora a percepção predominante seja positiva, com exceção da variável "Forma (s) de venda do (s) produto (s)", as demais apresentam algum grau de percepção das mesmas como fraqueza no que tange à gestão das unidades de produção, com destaque para aquelas relacionadas ao volume de produção e diversidade de produtos.

Convém ressaltar que as unidades de produção participantes da pesquisa são características da agricultura familiar, perfil preponderante em Santa Catarina. Feliciano et al (2015, p. 14) destaca que, com base nos dados do Censo Agropecuário de 2006, dos 193.663 estabelecimentos agropecuários no Estado de Santa Catarina, 171.111 (ou 88,3\%) possuem menos de 50 hectares de área. Além de se constituir num limite natural ao volume de produção, a restrição de área acaba influenciando a variável preço do produto, justamente pelo volume limitado de oferta, comprometendo o poder de negociação.

É interessante destacar que com a variável "Diversidade de produtos" buscava-se conhecer a percepção dos agricultores sobre a situação atual de seus sistemas produtivos, independente das características dos mesmos. Assim, levando-se em consideração que há uma predominância do cultivo de tabaco, é possível concluir que cerca de 3/4 das respostas ponderadas apontam tal situação como adequada às perspectivas dos agricultores entrevistados. 


\subsubsection{Gestão da informação}

Cabe ao gestor de cada unidade de produção e seus familiares buscar informações visando ampliar a capacidade competitiva dos seus negócios. No atual momento (sociedade da informação) esse elemento passou a ser percebido como de fundamental importância para a tomada de decisão e aplicação nos planos estratégicos em qualquer atividade econômica e social. Dessa forma, além das atividades rotineiras, os gestores das unidades de produção familiar necessitam reservar tempo para buscar informações sobre os seus negócios.

Mintzberg (2010, p.46), afirma que os gerentes eficazes não são aqueles com os maiores níveis de liberdade, mas sim, os que tiram vantagem de todo e qualquer nível de liberdade que encontram. Nessa toada, o autor considera que os gerentes bem informados são capazes de desenvolver mais rapidamente seus negócios e tomarem decisões mais acertadas.

Figura 9 - Percepção e grau de importância das variáveis internas relacionadas à gestão da informação.

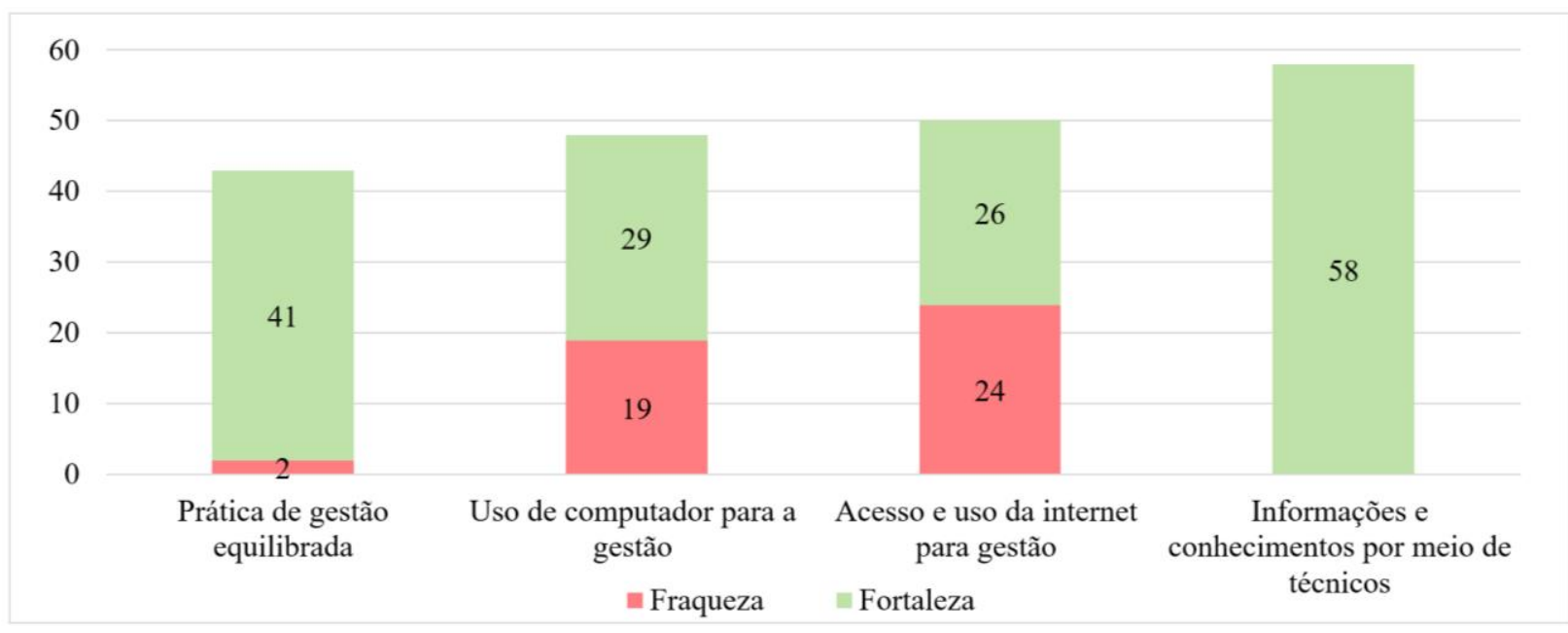

No que tange os resultados apresentados na Figura 9, os respondentes percebem a variável "Informações e conhecimentos por meio de técnicos" (assistência técnica e extensão rural) como muito importante na gestão dos negócios das unidades de produção. As demais ("Acesso e uso da internet para a gestão", "Uso do computador para a gestão" e "Prática de gestão equilibrada"), embora com pontuação um pouco menor, também foram percebidas como importantes à gestão das unidades de produção.

Apesar de serem consideradas importantes, as variáveis referentes ao acesso e uso da internet e uso do computador para a gestão representam as maiores fraquezas da gestão das unidades de produção participantes da pesquisa, com destaque para a primeira. $\mathrm{O}$ resultado apresentado para essa variável nos possibilita concluir que há limitações ou dificuldades para acesso à internet no meio rural do município de Canoinhas. 
No que diz respeito ao uso de computador e internet, baseado nos resultados, é possível afirmar que as unidades de produção participantes poderiam fazer uso desses recursos para implantação de ferramentas tecnológicas para facilitar a gestão do seu negócio, bem como acessar, analisar e armazenar dados. Ressalta-se que cerca de $40 \%$ dos entrevistados afirmaram utilizar a internet de alguma forma nos processos de gestão.

Mais uma vez destacamos que o uso desses instrumentos tecnológicos na gestão de propriedades agropecuárias consiste num fenômeno relativamente recente. Por outro lado, o meio rural brasileiro ainda enfrenta o problema da limitação infraestrutural em relação ao acesso à internet (bem como a outros serviços e infraestruturas, por óbvio), que passa a ser determinante na não aquisição de computadores.

\subsubsection{Gestão de pessoas}

O aparato tecnológico, a infraestrutura predial, os móveis e imóveis, são elementos importantes para a gestão organizacional, contudo, não mais importantes do que as pessoas. Cada vez mais ganha relevância na gestão o que acontece além daquilo realizado pelas pessoas, principalmente as que assumem papéis na gestão de negócios.

A Figura 10 apresenta os resultados da dimensão "Gestão de pessoas" nas unidades de produção agropecuária familiar pesquisadas. Dentre as variáveis que compõem essa dimensão, apenas "Participação em entidades" é percebida como tendo importância média no que tange a gestão das unidades de produção, sendo todas as demais consideradas muito importantes.

Figura 10 - Percepção e grau de importância das variáveis internas relacionadas à gestão de pessoas.

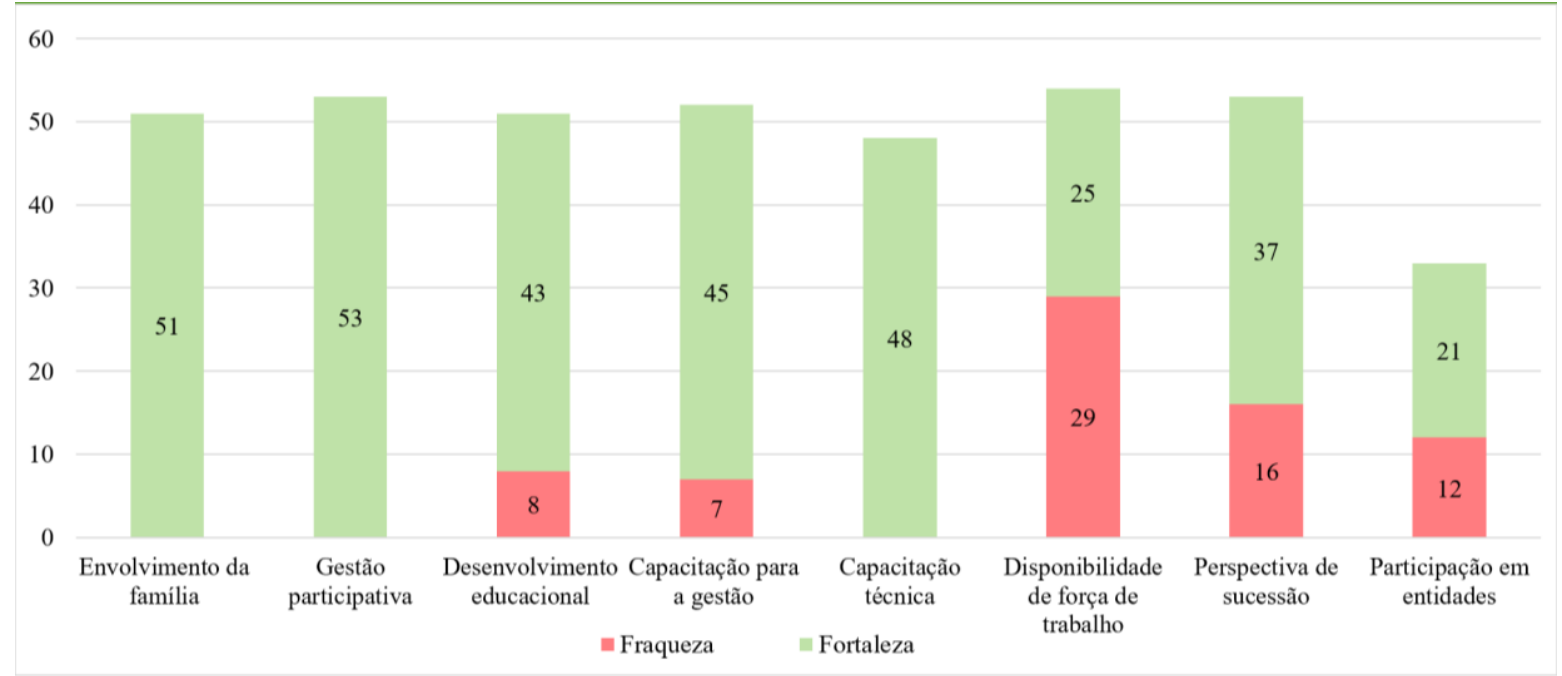


As variáveis "Envolvimento da família", "Gestão participativa" e "Capacitação técnica", além de serem consideradas muito importantes, foram unanimemente percebidas como fortalezas na gestão das unidades.

Nessa mesma perspectiva, as variáveis "Desenvolvimento educacional" e “Capacitação para a gestão", além de consideradas muito importantes, apresentam baixos índices de percepção negativa, conforme pode ser observado no gráfico anterior.

A variável "Participação em entidades" (considerada de importância média) foi percebida como fraqueza na gestão das unidades de produção por cerca de $36 \%$ dos participantes da pesquisa, merecendo maior atenção em investigações futuras.

Quanto a isso, é importante ressaltar que a pesquisa de campo demonstrou que somente $1 / 3$ dos entrevistados relataram participar de alguma associação, enquanto $10 \%$ participam de alguma cooperativa.

A "Disponibilidade de força de trabalho" foi percebida majoritariamente como fraqueza na gestão das unidades de produção. Tal dado contrasta por um lado com os dados de disponibilidade de UTH apresentados na caracterização das unidades de produção (4.1) e, por outro, com a baixa disponibilidade de área, problema do qual trataremos no tópico 4.3.6.

Já a variável "Perspectiva de sucessão" recebeu uma valorização elevada, sendo considerada uma fraqueza por quase $30 \%$ das respostas ponderadas.

Não se pode deixar de ressaltar que tal percentual, embora significativo, está aquém do desejável, levando em consideração os diversos estudos que tratam da problemática da sucessão na agricultura familiar, tema que também é abordado em algumas políticas públicas.

\subsubsection{Finanças e custos}

Das dimensões do ambiente interno, "Finanças e custos" apresentou a segunda pior pontuação média ponderada (46,75), ficando à frente somente de “Gestão ambiental". Por outro lado, foi a dimensão que apresentou maior percentual de sua pontuação caracterizada como fortaleza $(95 \%)$.

Chama a atenção também que das 8 variáveis, 5 foram consideradas unanimemente como fortalezas e 2 apresentaram baixíssima menção à fraqueza. 
Figura 11 - Percepção e grau de importância das variáveis internas relacionadas à finanças e custos.

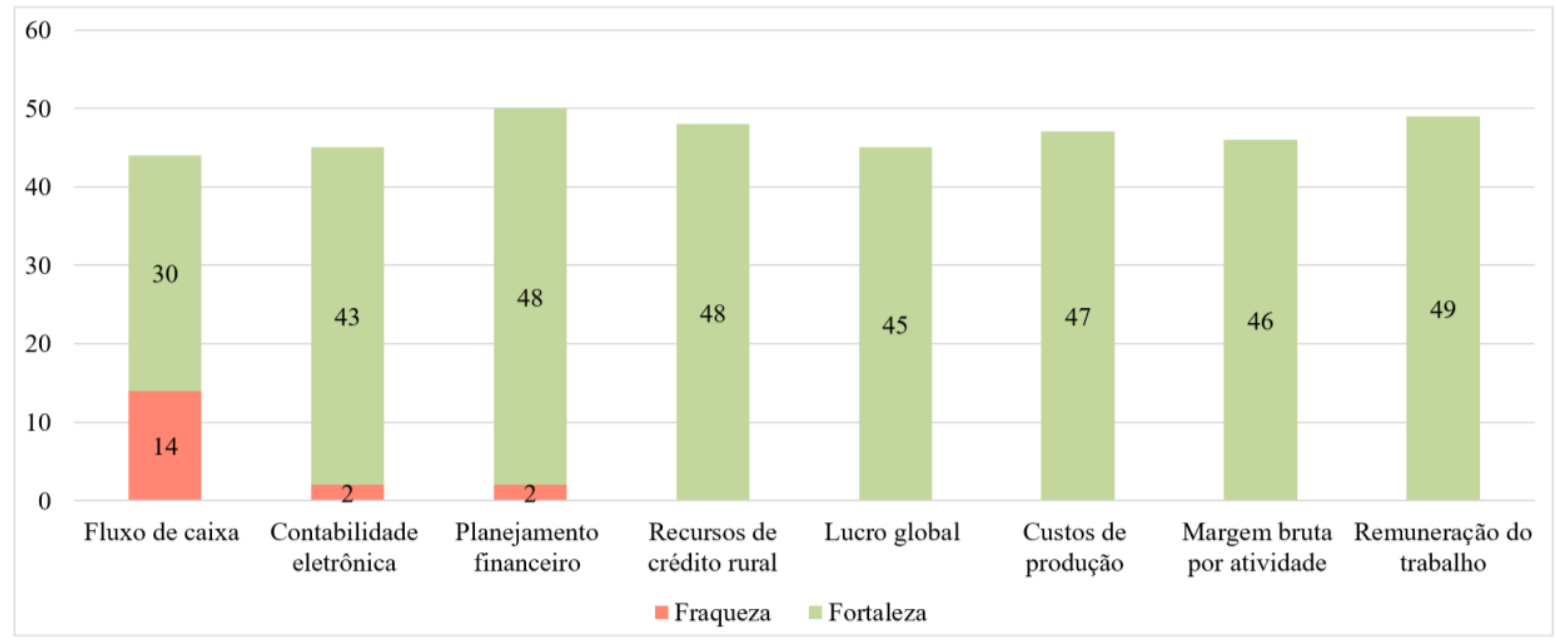

Como é possível perceber no gráfico anterior, nenhuma das variáveis apresentou grande destaque em relação às demais ou foi responsável isoladamente pela baixa pontuação.

Embora as variáveis desta dimensão tenham recebido uma pontuação menor que a maioria das demais do ambiente interno, ainda assim os valores são significativos. Além disso, no caso do "Conhecimento do lucro global", "Conhecimento dos custos de produção", "Conhecimento da margem bruta por atividade" e "Conhecimento da remuneração do trabalho", a totalidade das respostas classificou essas variáveis como pontos fortes das unidades de produção. Ou seja, há a percepção de que o conhecimento desses indicadores econômicos é importante e eles vem contribuindo positivamente para a gestão das unidades.

De modo semelhante, o uso de recursos de crédito rural e de outras políticas de fomento para a agricultura familiar obteve pontuação semelhante às variáveis anteriores, sendo também considerado unanimemente uma fortaleza. Tal situação indica que não há problemas de acesso ao crédito e outras políticas consideradas relevantes pelos agricultores (ou, pelo menos, não há percepção disso).

O uso de sistemas de contabilidade eletrônica e o planejamento financeiro também se mostraram importantes, embora com pequenos índices de percepção negativa (4,4\% e 4,0\%, respectivamente). É importante destacar que todas as unidades participantes desta pesquisa fazem uso do software Contagri para sua gestão, bem como realizam planejamento anual das atividades. $\mathrm{O}$ resultado obtido reforça a importância e valorização desse instrumento.

A única variável que obteve um índice mais significativo de percepção como ameaça (cerca de 32\%) foi o "Fluxo de caixa", o que indica que, não obstante a importância do mesmo, esse mecanismo não vem sendo utilizado de forma adequada ou suficiente. 


\subsubsection{Gestão ambiental}

Conforme citado anteriormente, "Gestão ambiental" foi a dimensão que obteve a menor pontuação média ponderada $(43,88)$, principalmente em decorrência das variáveis "Educação ambiental" e "Dejetos animais", avaliados como de importância somente média, conforme é possível perceber na Figura 12.

Figura 12 - Percepção e grau de importância das variáveis internas relacionadas à gestão ambiental.

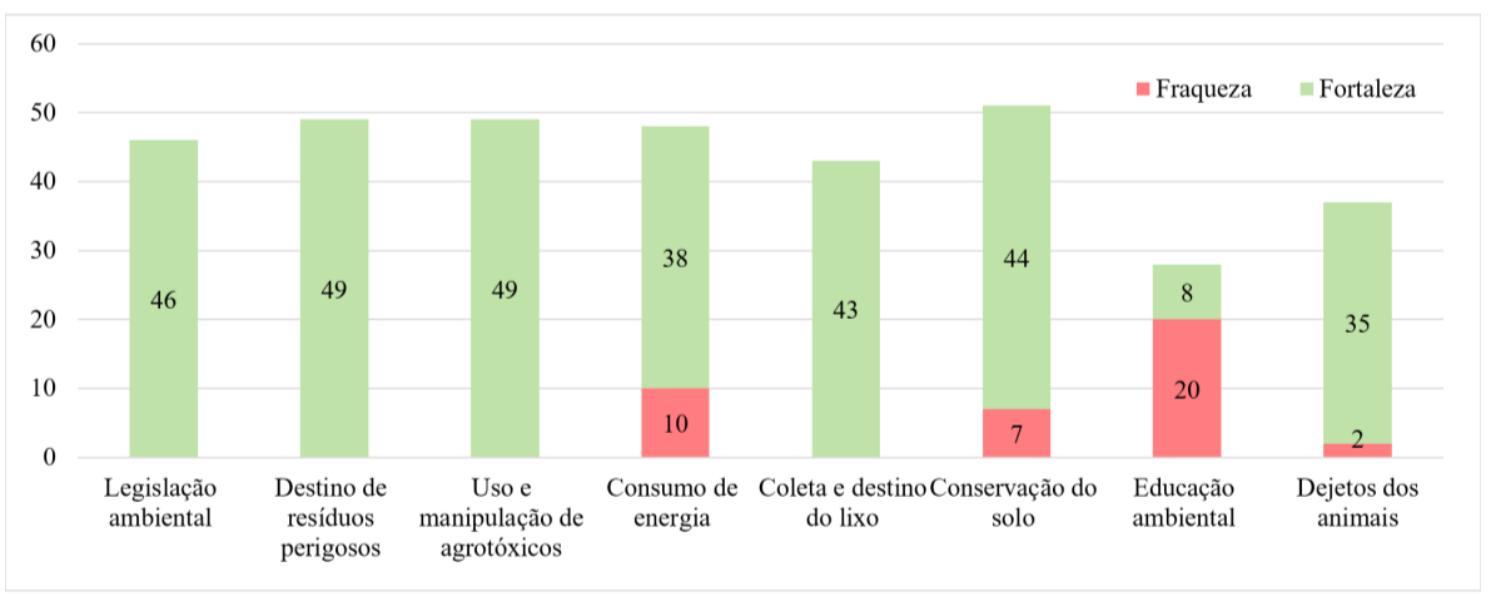

Não obstante o fato da pontuação relativamente baixa, chama a atenção nesta dimensão o fato de 4 variáveis terem sido avaliadas unanimemente como fortalezas. Dentre essas encontra-se "Legislação ambiental”. É recorrente que o tema legislação ambiental tenha uma conotação negativa no meio rural, conforme já comentado anteriormente, em decorrência de conflitos entre a produção e a conservação ambiental. A priori, tal percepção indicaria que as propriedades estão adequadas à legislação ambiental ou, caso contrário, que isso não é visto como um problema.

As variáveis "Destino dos resíduos perigosos" e "Uso e manipulação de agrotóxicos" também foram unanimemente consideradas fortalezas. A se confirmar no cotidiano a percepção que os agricultores têm da forma como lidam com os agrotóxicos, é possível afirmar que a maioria acredita adotar práticas adequadas no uso, armazenamento e destinação de embalagens desses produtos.

Contudo, um dos resultados mais surpreendentes dessa dimensão é a percepção de "Coleta e destino do lixo", unanimemente considerada um ponto forte. Em geral, os serviços de coleta de lixo atuam somente no meio urbano, o que força os agricultores a adotarem manejos alternativos para o lixo. Contudo, 100\% dos agricultores entrevistados nesse 
município percebem essa variável de forma positiva. Há que se buscar compreender o que motivou tal compreensão.

"Consumo de energia" apresentou uma percepção negativa em pouco mais de $20 \%$ das respostas ponderadas. Vale lembrar que todos os agricultores participantes desta pesquisa produzem tabaco, realizando a secagem desse produto em estufas. Essa etapa demanda grande quantidade de madeira e seu grau de eficiência pode comprometer a lucratividade da atividade. Acredita-se que tal fator deve ter contribuído na atribuição de importância dessa variável, sendo a mesma considerada problemática para 1/5 dos entrevistados.

A variável "Conservação do solo" foi a que obteve a maior pontuação nesta dimensão, sendo majoritariamente percebida como fortaleza (86,3\% das respostas ponderadas). Há diversos fatores que podem ajudar a explicar tal resultado, mas é inegável que as campanhas e ações de cunho conservacionista têm uma parcela de contribuição nisso.

Por fim, as duas últimas variáveis foram as que obtiveram menor pontuação. "Dejetos animais" obteve 37 pontos, sendo majoritariamente percebida como ponto forte. Isso se explica pela baixa presença de animais nas propriedades, o que fica explícito pela sua reduzida participação na composição da renda.

Já "Educação ambiental”, além de ser uma das variáveis com menor pontuação nesta pesquisa, é percebida como um ponto fraco por $71,4 \%$ das respostas ponderadas. Isso indica que a participação em atividades de educação ambiental é percebida como problemática pela maioria dos entrevistados, embora eles não lhes atribuam muita importância.

\subsubsection{Gestão da produção}

Esta dimensão obteve a maior pontuação média ponderada do ambiente interno, não obstante o fato de abrigar a variável com a menor pontuação. Para fins de análise, as variáveis que compõem esta dimensão podem ser agrupadas em quatro grupos. Num primeiro grupo estão aquelas relacionadas às condições naturais das unidades de produção: "Condições do solo", "Quantidade e qualidade da água" e "Condições climáticas". Todas receberam pontuações elevadas, destacando-se as condições climáticas, com 52 pontos. Por outro lado, essa variável foi também a única que apresentou algum grau de percepção negativa $(15,4 \%)$. Assim, é possível concluir que as condições naturais são valorizadas no processo de gestão das unidades de produção, mas de forma geral não se constituem num fator limitante (ao menos na percepção dos gestores entrevistados). 
Figura 13 - Percepção e grau de importância das variáveis internas relacionadas à gestão da produção.

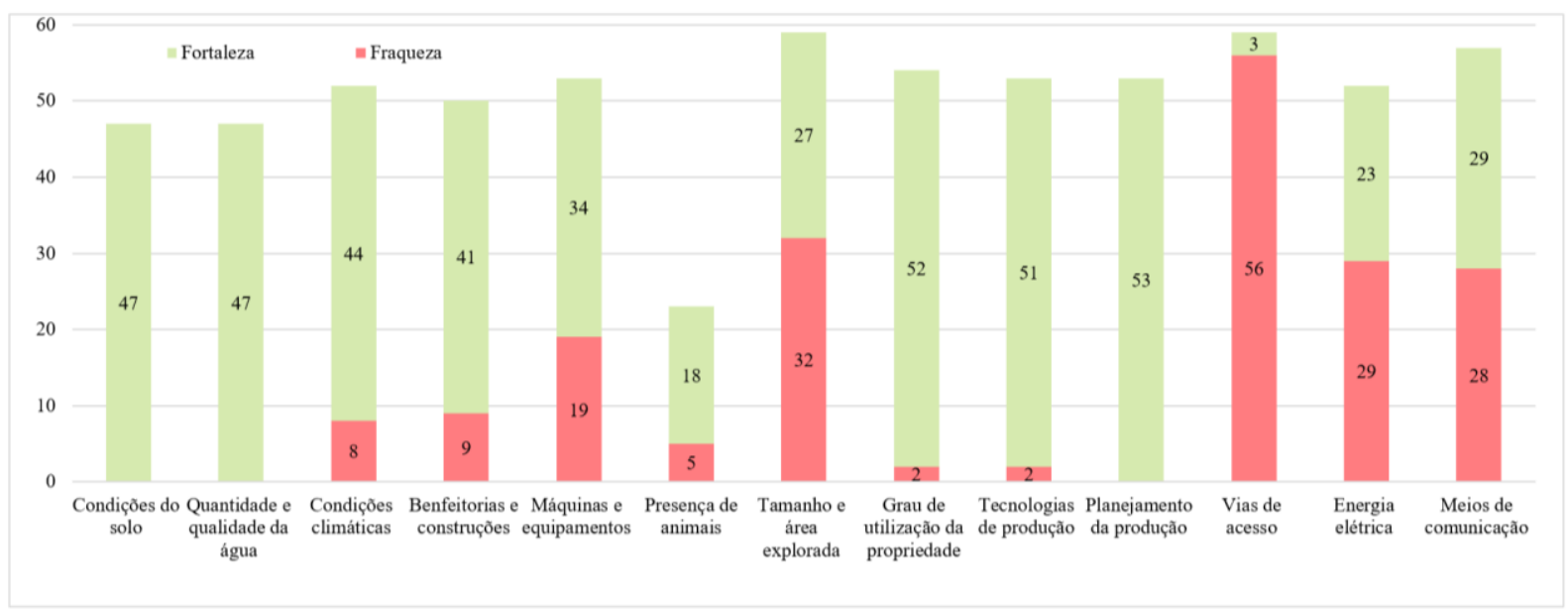

No segundo grupo pode-se agregar as variáveis que dizem respeito às estruturas produtivas disponíveis nas unidades: "Benfeitorias e construções", "Máquinas e equipamentos", "Presença de animais" e "Tamanho e área explorada". As duas primeiras foram bastante valorizadas, apresentando também índices de percepção negativa significativos (18\% e 35,8\%, respectivamente), o que demonstra que as benfeitorias, máquinas e equipamentos são fatores importantes, mas se apresentam com algum grau de fragilidade no caso dos agricultores participantes desta pesquisa. A baixa pontuação da variável relacionada à presença de animais explica-se pela pequena participação destes na composição da renda das unidades nessa região. Contudo, a variável que mais chama a atenção é "Tamanho e área explorada", que atingiu pontuação próxima do máximo, mas é percebida como ponto fraco por mais da metade das respostas ponderadas (54,2\%). Tal cenário indica que há limitação de acesso à terra. É importante destacar que a percepção leva em consideração não apenas fatores objetivos (efetiva disponibilidade de área), mas também os anseios e condições de trabalho dos agricultores.

Já o terceiro grupo de variáveis está relacionado à forma de utilização da unidade de produção: "Grau de utilização da propriedade", "Tecnologias de produção" e "Planejamento da produção". Todas elas obtiveram pontuações elevadas e muito semelhantes, predominando ainda uma percepção fortemente positiva em relação a esses aspectos, conforme demonstra o gráfico. A elevada pontuação atribuída ao grau de utilização condiz com a percepção da variável relativa ao tamanho da propriedade, analisada anteriormente. Isso significa que há uma percepção predominante de que as áreas são insuficientes para o que se deseja, mas dentro das possibilidades são intensamente utilizadas nas atividades produtivas. A valorização 
do uso de tecnologias de produção também aponta para a importância do papel da ATER, não obstante o fato da grande maioria considerar o grau atual de uso de tecnologias uma fortaleza.

Por fim, o conjunto de variáveis relacionadas às infraestruturas de apoio à produção agropecuária é composto por "Vias de acesso", "Energia elétrica" e "Meios de comunicação". Todas foram bastante valorizadas pelos entrevistados, destacando-se também a predominância da percepção de fraqueza nesse conjunto. "Vias de acesso", por exemplo, que obteve uma pontuação próxima do máximo (ou seja, é um fator muito importante para os gestores das unidades), é percebida como fraqueza por $94,9 \%$ das respostas ponderadas. Isso demonstra que as estradas do município devem se constituir num problema bastante sério. Mesmo a variável "Energia elétrica", que não surgiu como problema significativo em pesquisas semelhantes realizadas em outras regiões do estado, neste caso é apontada como fraqueza por mais da metade dos respondentes (55,8\%). O menos problemático parece ser a disponibilidade de meios de comunicação que, ainda assim, foi percebida como ponto fraco por $49,1 \%$ das respostas ponderadas. Há que se avaliar as condições de infraestrutura da região para tentar compreender melhor as respostas obtidas na pesquisa de campo.

\section{CONSIDERAÇÕES FINAIS}

A sustentabilidade das unidades de produção agropecuária depende de sua capacidade de construir conexões em vários elos da cadeia produtiva na qual estão inseridas, o que implica muitas vezes em modificar a forma da unidade produtiva se autogerir. $\mathrm{O}$ olhar tem que estar voltado para o interno e também para o externo, o que faz com que as decisões tenham de ser pautadas cada vez mais em análises mais amplas, que se dão em universo construído coletivamente a partir da interação em espaços sociais os mais diversos.

Partindo-se dos dados apresentados neste artigo, é possível afirmar que os gestores percebem as variáveis consideradas do ambiente externo mais como oportunidades, mas com certo equilíbrio em relação à representação das mesmas como ameaças. Já as variáveis do ambiente interno são percebidas de maneira significativa como fortalezas. Tais resultados não chegam a ser surpreendentes, uma vez que as fortalezas tendem a ser sobrevalorizadas e, portanto, em geral são mais estreitas do que o percebido, e as fraquezas comumente são subdimensionadas, sendo muitas vezes mais amplas do que uma análise superficial é capaz de perceber. Além disso, a maior presença de percepções negativas no ambiente externo 
(ameaças) está associada à menor previsibilidade e possibilidade de controle desse ambiente, principalmente num momento de instabilidade política, econômica e social.

De forma geral, é possível afirmar que nenhuma das variáveis isoladamente captura a essência da gestão dentro do contexto que envolve a unidade de produção, sendo necessário considerá-las no seu conjunto. Mesmo aquelas que obtiveram pontuações menores, se mostraram com grau significativo, não sendo razoável desconsiderá-las para a compreensão da prática da gestão nas unidades analisadas.

Além disso, há que se levar em conta que a percepção dos gestores das unidades está muitas vezes associada a fatores conjunturais, não sendo possível desconsiderar o contexto em que se dão os processos de gestão para a interpretação dos mesmos. As percepções apresentadas no presente artigo, por exemplo, certamente guardam relação com a conjuntura atual, marcada por incertezas no ambiente econômico e político, o que tende a conferir um viés mais negativo aos fatores não controláveis (relacionados principalmente ao ambiente externo), em especial aqueles associados ao ambiente político e macroeconômico.

É importante destacar que não se desconhece a existência de outras variáveis relevantes que poderiam ser incorporadas na presente pesquisa, muitas delas associadas a fatores subjetivos e que não se explicitaram neste artigo. Tal análise certamente poderá se fazer presente em futuros estudos. Além disso, é importante ressaltar a necessidade de novas análises junto ao grupo ora pesquisado, buscando compreender as motivações das percepções aqui relatadas.

Pensar novas estratégias e produzir inovações são alguns dos desafios da gestão, no sentido de facilitar a reprodução social de unidades de produção familiar para os próximos anos. Para enfrentá-los, utilizar o conhecimento coletivo de um grupo de gestores de unidades de produção pode ser interessante para que eles mesmos possam responder aos desafios e às oportunidades estratégicas. Nesse processo de enfrentamento, deve-se utilizar da inteligência, da criatividade e dar a devida atenção à formulação do problema, evitando-se gastar energia na busca de uma solução para um problema errado.

\section{REFERENCIAS}

BATALHA, Mário Otávio; BUAINAIN, Antônio Márcio; SOUZA FILHO, Hildo Meirelles de. Tecnologia de gestão e agricultura familiar. BATALHA, M.O. e SOUZA FILHO, H.M. de (org). Gestão Integrada da Agricultura Familiar. São Carlos. EdUFSCar, 2005.

CRAINER, Stuart; DEARLOVE, Des. Gestão: como envolver e motivar a equipe para o sucesso. Bookman Editora, 2014. 
DRUCKER, Peter Ferdinand. As fronteiras da administração. Rio de Janeiro: Elsevier, 2012.

FELICIANO, Antônio Marco; SANTOS, Alex Alves dos; MARCONDES, Tabajara; TORESAN, Luiz; ALVES, João Rogério; DOROW, Reney; PADRÃO, Gláucia Almeida; GOULART JUNIOR, Rogério. Números da Agropecuária Catarinense. Epagri: Florianópolis, 2015.

GIEHL, Alexandre Luis. Entre o extraordinário e o cotidiano: os processos decisórios dos agricultores assentados: Um estudo de caso do Assentamento Domingos Carvalho (Rio Negrinho/SC). 234 f. Dissertação (Mestrado) - Agroecossistemas, UFSC, Florianópolis, 2002.

IBGE. Instituto Brasileiro de Geografia e Estatística. Censo Agropecuário de 2006. Disponível em: http://www.ibge.gov.br/home/estatistica/economia/agropecuaria/censoagro/. Acesso em: 14 de abr. 2016.

MINTZBERG, Henry. Managing: desvendando o dia a dia da gestão. Bookman, 2010.

MINTZBERG, Henry; AHLSTRAND, Bruce; LAMPEL Joseph. Safári de Estratégia: Um Roteiro pela Selva do Planejamento Estratégico. $2^{\mathrm{a}}$ ed. Bookman Editora, 2010.

NICOLAU, Isabel. O conceito de estratégia. INDEG/ISCTE, 2001.

SECCHI, Leonardo. Drucker no ensino de administração: um alerta necessário. Organizações \& Sociedade, v. 11, n. 31, p. 13-23, 2004.

WILKINSON, John. Prefácio. In: ESTEVAM, D. de O.; MIOR, L.C. (Orgs.). Inovações na agricultura familiar: as cooperativas descentralizadas em Santa Catarina. Florianópolis: Insular. 2014. 